\title{
Novel Insecticides from Alkylated and Acylated Derivatives of Thymol and Eugenol for the Control of Plutella xylostella (Lepidoptera: Plutellidae)
}

\author{
Claudio A. G. da Camara, ${ }^{\circ * a}$ Bogdan Doboszewski, ${ }^{a}$ João P. R. de Melo, ${ }^{a}$ \\ Alexander Y. Nazarenko, ${ }^{\circledR b}$ Rodrigo B. dos Santos ${ }^{a}$ and Marcilio M. Moraes ${ }^{a}$ \\ ${ }^{a}$ Departamento de Química, Universidade Federal Rural de Pernambuco, \\ Rua Dom Manoel de Medeiros s/n, 52171-030 Recife-PE, Brazil \\ ${ }^{b}$ Chemistry Department, State University of New York, College at Buffalo, \\ 1300 Elmwood Ave., 14222 Buffalo, NY, USA
}

\begin{abstract}
Plutella xylostella cause considerable harm to the production of broccoli, Chinese cabbage, cabbage and cauliflower. The control of $P$. xylostella is mainly performed using commercial insecticides, which have even led to the emergence of resistant populations. Two easily available natural products found in different plants essential oil, thymol and eugenol, stand up as possible novel agents to control this pest. In this work a series of alkylated and acylated derivatives of eugenol and thymol were synthesized and screened for antifeedant, larvicidal and ovicidal activities against $P$. xylostella. The results of biological activities assays suggest that the novel $1,1^{\prime}$-[1,8-octanediylbis(oxy)]-bis(4-allyl-2-methoxy-benzene) (5) was the most toxic in the larvicidal test. Compounds 1-butoxy-2-isopropyl-5-methyl-benzene (8) and hexanedioic acid 1,6-bis(2-isopropyl-5-methyl-phenyl)-ester (10) were the most toxic in the ovicidal assay. The compound $\mathbf{8}$ presented the most antifeedant activity. Most of the compounds obtained were more active than commercially available insecticidal deltamethrin and azadirachtin.
\end{abstract}

Keywords: antifeedant, eugenol, insecticidal, larvicidal, Plutella xylostella, thymol

\section{Introduction}

Agricultural pests limit the output of different crops due to the harm caused, which reduces productivity and depreciates the commercial value of the product. Larvae of the diamond-back moth Plutella xylostella (L.) (Lepidoptera: Plutellidae) cause considerable harm to the production of broccoli, Chinese cabbage, cabbage and cauliflower. ${ }^{1}$ The losses caused by this pest lead to an annual deficit of US\$ 105 million to Brazilian producers. ${ }^{2}$ The control of P. xylostella is mainly performed through the use of synthetic chemical products, such as deltamethrin, which do not have the expected effectiveness and have even led to the emergence of resistant populations of P. xylostella ${ }^{3}$

A search for novel agents to the control of $P$. xylostella is therefore important. Two easily available natural products, thymol and eugenol, are possible alternative model compounds for such research since both display insecticidal activity. Thymol is a major component of the essential oils

*e-mail: claudio_agc@hotmail.com

Editor handled this article: Teodoro S. Kaufman from Lippia sidoides Cham., Oliveria decumbens Vent. and Thymus longicaulis subsp. Longicaulis. ${ }^{4-6}$ Eugenol is the major component of the oils from Syzygium aromaticum $\mathrm{L}$. and Ocimum campechianum Mill. ${ }^{7,8}$ Investigations of the biological action of both compounds have demonstrated that thymol and eugenol have potent insecticidal activity including the larvae of P. xylostella.$^{9-12}$ Besides insecticidal action, the repellent action of these compounds against the agricultural pests (Diaphania hyalinata L.) and Tetranychus urticae has recently been reported. ${ }^{13,14}$ Pandiyan et al. ${ }^{15}$ reported the larvicidal action of thymol and eugenol against the mosquito Aedes aegypti, which is a vector of different diseases, such as dengue and zika.

Since eugenol and thymol are cheap and commercially available, modification of the structures of both is an attractive way to modulate the biological activity of these compounds against $P$. xylostella. The aim of the present study was to obtain a series of alkylated and acylated derivatives of these natural products and determine their larvicidal, ovicidal and antifeedant activity against P. xylostella. Since there is no published data on alkylated or acylated derivatives of eugenol and thymol in terms of the 
insecticidal activity, any alkyl and acyl derivative of both is of potential value to conduct the screening. The results were compared with those obtained using the starting materials (thymol and eugenol) and deltamethrin and azadirachtin, used as positive controls.

\section{Experimental}

\section{Chemicals}

All solvents and reagents used were purchased from commercial sources (Sigma-Aldrich $^{\circledast}$, São Paulo, Brazil) and used without further purification. Reactions were carried out under argon atmosphere. Reactions were monitored by thin layer chromatography (TLC) analysis on precoated silica gel plates $(0.2 \mathrm{~mm}$ with fluorescent indicator) (Kieselgel 60F254, Merck, São Paulo, Brazil) and compounds were visualized with ultraviolet (UV) light. Column chromatography (CC) was performed on silica gel SI 60 (70-230 mesh, Merck, São Paulo, Brazil). Melting points were measured in open capillary tubes in a PFMII BioSan apparatus (BioSan, São Paulo, Brazil).

Synthesis of derivatives of the eugenol (1-3) and thymol (8)

Butyl bromide, 1-bromo-decane, 1-bromo-hexadecane were employed for the synthesis of derivatives of the eugenol and thymol (1-3 and 8). For this, a solution composed of eugenol (1.2-2.3 mmol) or thymol, $\mathrm{K}_{2} \mathrm{CO}_{3}(4.7-5.0 \mathrm{mmol})$, alkyl halides (0.5-1.9 mmol) and catalytic quantity of $\mathrm{Bu}_{4} \mathrm{NHSO}_{4}$ in $\mathrm{CH}_{2} \mathrm{Cl}_{2}$ were magnetically stirred during $48 \mathrm{~h}$ at $50{ }^{\circ} \mathrm{C}$. The reactions were monitored by thin layer chromatography eluted with hexane:ethyl acetate (5:1) and the chromatographic plates were visualized under UV light. The reaction was finished when eugenol was not detected in the TLC plates anymore. Thus, the reaction was partitioned employing $\mathrm{CH}_{2} \mathrm{Cl}_{2}$ and the organic layer was rinsed successively with $\mathrm{HCl}\left(10 \mathrm{~mol} \mathrm{~L}^{-1}\right)$ and $\mathrm{NaHCO}_{3}(5 \%)$ aqueous, then $\mathrm{Na}_{2} \mathrm{SO}_{4}$ was added, filtered and the solvent submitted to vacuum evaporation. After filtration, the solvent was evaporated and the derivatives were purified using CC (silica gel) and hexane:ethyl acetate (8:2) as eluents.

\section{Synthesis of derivatives of the eugenol (4 and 5)}

The 1,4-dibromobutane and 1,8-dibromoctane were employed for the synthesis of derivatives of the eugenol 4 and 5, respectively. Eugenol $(2.0 \mathrm{mmol})$, alkyl halides $(0.54 \mathrm{mmol})$, in dioxane $(2.5 \mathrm{~mL})$, polyethylene glycol $(0.1 \mathrm{~mL})$ and $40 \% \mathrm{KOH}(0.2 \mathrm{~mL})$ were magnetically stirred during $48 \mathrm{~h}$. The reactions were monitored by thin layer chromatography eluted with hexane:ethyl acetate (5:1) and the chromatographic plates were visualized under UV light. The phases were separated and aqueous phase was extracted with $\mathrm{CH}_{2} \mathrm{Cl}_{2}$. Combined organic phases were evaporated to leave a solid material which was washed with water. The residue was purified by chromatography (hexane:EtOAc 9:1) and crystallized in order to obtain the pure derivatives.

Synthesis of derivatives of the eugenol (7) and thymol (9)

Eugenol or thymol $(1.5 \mathrm{mmol})$, in dry pyridine $(1.5 \mathrm{~mL})$, was cooled in ice-water bath under argon atmosphere. To this decanoyl chloride $(1.75 \mathrm{mmol})$ was added, under the argon atmosphere while maintaining magnetic stirring. The mixture was kept overnight at room temperature (rt). The reactions were monitored by thin layer chromatography eluted with hexane:ethyl acetate (4:1) and the chromatographic plates were visualized under UV light. Extractive work-up (dil. $\mathrm{HCl}: \mathrm{CH}_{2} \mathrm{Cl}_{2}$ ), drying of the organic phase $\left(\mathrm{MgSO}_{4}\right)$, filtration of the solids and evaporation of volatiles left an oil which was purified by column chromatography using a gradient of hexane:ethyl acetate 9:1.

Synthesis of derivatives of the eugenol (6) and thymol (10)

Eugenol or thymol $(1.5 \mathrm{mmol})$, in pyridine $(1.5 \mathrm{~mL})$, was cooled in ice-water bath under argon atmosphere, then adipoyl chloride $(0.8 \mathrm{mmol})$ was added using a syringe while maintaining the atmosphere of dry argon and magnetic stirring. The mixture was left overnight at rt. The reactions were monitored by thin layer chromatography eluted with hexane:ethyl acetate (4:1) and the chromatographic plates were visualized under UV light. Extractive work-up (dil. $\left.\mathrm{HCl}: \mathrm{CH}_{2} \mathrm{Cl}_{2}\right)$, drying of the organic phase $\left(\mathrm{MgSO}_{4}\right)$, filtration of the solids and evaporation of volatiles left an oil which was purified by column chromatography using a gradient of hexane:ethyl acetate 9:1.

${ }^{1} \mathrm{H}$ and ${ }^{13} \mathrm{C}$ nuclear magnetic resonance (NMR) spectra were obtained on Varian Unity Plus spectrometer (Palo Alto, USA) (300 MHz for ${ }^{1} \mathrm{H}$ and $75 \mathrm{MHz}$ for ${ }^{13} \mathrm{C}$ ) and a Varian Unity Plus spectrometer (Palo Alto, USA) $(400 \mathrm{MHz}$ for ${ }^{1} \mathrm{H}$ and $100 \mathrm{MHz}$ for ${ }^{13} \mathrm{C}$ ). Deuterated chloroform $\left(\mathrm{CDCl}_{3}\right)$ was used as solvent, and tetramethylsilane (TMS) was used as the internal standard. Chemical shifts $(\delta)$ were measured in parts per million ( $\mathrm{ppm})$, and the coupling constants $(J)$ were measured in hertz $(\mathrm{Hz})$. High-resolution mass spectrometry spectra (HRESIMS) were performed using the Exactive Plus HCD Thermo Scientific mass spectrometer (Waltham, USA). The mass spectrometer (MS) was operating in the positive ion mode 
with mass range of $m / z$ 50-1000. The standard electrospray ion (ESI) source was used to generate the ions. The mass spectra were acquired by direct sample injection $\left(180 \mu \mathrm{L} \mathrm{min}{ }^{-1}\right)$ with nebulization temperature of $180{ }^{\circ} \mathrm{C}$. The gas chromatography-mass spectrometry (GC-MS) analysis was carried out using a GC-EM QP2010 SE Plus Shimadzu Chromatograph system (Kyoto, Japan) with a mass selective detector, a mass spectrometer in electron impact (EI) $70 \mathrm{eV}$ with a scan-interval of $0.5 \mathrm{~s}$, and fragments from 40-550 Da. A non-polar fused silica capillary column DB-5 $(30 \mathrm{~mm} \times 0.25 \mathrm{~mm} \times 0.25 \mu \mathrm{m})$ was used. The oven temperature was programmed to increase from 100 to $290{ }^{\circ} \mathrm{C}$ at a rate of $7{ }^{\circ} \mathrm{C} \mathrm{min}{ }^{-1}$. The injector and detector temperatures were set at $260^{\circ} \mathrm{C}$. Helium was used as the carrier gas at a flow rate of $1 \mathrm{~mL} \mathrm{~min}^{-1}$; split mode of 1:30; volume injected in auto-injector AOC-20i was of $1 \mu \mathrm{L}$ of a diluted solution (1/100) of compound in chloroform.

\section{Acquisition and rearing Plutella xylostella}

Specimens of Plutella xylostella (L.) (Lepidoptera: Plutellidae) was originally collected from collard greens (Brassica oleracea var. acephala) in the municipality of Recife, Pernambuco State (0801'08.3” S, 3456'45.5” W), and maintained at the Laboratory for the Chemical Investigation of Natural Insecticides of Rural Federal University of Pernambuco, Brazil. P. xylostella were rearing at a temperature of $25 \pm 1{ }^{\circ} \mathrm{C}$, relative humidity of $65 \pm 5 \%$ and $12 \mathrm{~h}$ photoperiod and without any exposure to insecticides. The breeding method was adapted from Robertson et al. ${ }^{16}$

\section{Larvicidal assay with Plutella xylostella}

The residual effect bioassays were based on the method described. ${ }^{17}$ Experiments were performed with open Petri dishes $(10 \mathrm{~cm}$ in diameter $)$. Leaf discs $(2.5 \mathrm{~cm}$ in diameter) cut from collard greens were immersed for $30 \mathrm{~s}$ in the solutions prepared with essential oil, diluted in an aqueous solution (distilled water $+1.0 \%$ polyoxyethylene sorbitan monolaurate $+0.1 \%$ dodecylbenzene sulfonic acid), applied using the immersion method and allowed to dry on a paper towel at room temperature for $30 \mathrm{~min}$. Ten third instar $P$. xylostella larvae were placed in each dish. The experimental design was entirely randomized, totaling 120 larvae per treatment. The concentrations ranged from 0.30 to $12.00 \mathrm{mg} \mathrm{L}^{-1}$ (compounds $\mathbf{1 - 4}$ and 7-9), 0.10 to $15.00 \mathrm{mg} \mathrm{L}^{-1}$ (compounds 5, 6 and 10), 2.00 to $50.00 \mathrm{mg} \mathrm{L}^{-1}$ (azadirachtin) and 1.00 to $25.00 \mathrm{mg} \mathrm{L}^{-1}$ (deltamethrin). Mortality was recorded after $48 \mathrm{~h}$ of exposure. P. xylostella with no sign of movement were considered dead.
Negative control disks were only immersed in an aqueous solution (distilled water $+1.0 \%$ polyoxyethylene sorbitan monolaurate $+0.1 \%$ dodecylbenzene sulfonic acid).

\section{Ovicidal assay with Plutella xylostella}

The ovicidal bioassay was the same as that employed by Zago et al., ${ }^{18}$ with some modifications. Ten recently emerged male-female pairs of $P$. xylostella were placed in screened recipients containing leaf disks $(2.5 \mathrm{~cm}$ in diameter) of collard greens for oviposition. At six-hour intervals, the leaf disks were removed from the recipients. Thirty eggs were counted and the remaining eggs were removed. Leaf disks with 30 eggs were immersed for $30 \mathrm{~s}$ in different concentrations of the essential oils and positive controls (azadirachtin and deltamethrin) diluted in an aqueous solution (distilled water $+1.0 \%$ polyoxyethylene sorbitan monolaurate $+0.1 \%$ dodecylbenzene sulfonic acid). The concentrations ranged from 1.00 to $150.00 \mathrm{mg} \mathrm{L}^{-1}$ (compounds 2-5 and 9), 0.05 to $15.00 \mathrm{mg} \mathrm{L}^{-1}$ (compounds $\mathbf{1}$, 6-8 and 10), 2.00 to $50.00 \mathrm{mg} \mathrm{L}^{-1}$ (azadirachtin) and 20.00 to $100.00 \mathrm{mg} \mathrm{L}^{-1}$ (deltamethrin). Negative control disks were only immersed in the aqueous solution. After drying at room temperature for $30 \mathrm{~min}$, the leaf disks containing the eggs were placed on filter paper on sponge saturated with water in plastic trays and kept in a climatic chamber (BCCL-403-C, BioLAB, Toronto, Canada) at $25 \pm 1{ }^{\circ} \mathrm{C}$ and $70 \pm 10 \%$ relative humidity. Egg viability was evaluated $96 \mathrm{~h}$ after exposure to the substances through counts of the number of hatched larvae.

\section{Antifeedant assay with Plutella xylostella}

The feeding deterrence method was adapted from Akhtar et al. ${ }^{19}$ Third instar P. xylostella larvae were transferred to Petri dishes and deprived of food for four hours prior to the experiments. Collard leaf disks $(2.0 \mathrm{~cm}$ diameter) were immersed for $30 \mathrm{~s}$ in the solutions prepared with essential oil and positive control, diluted in distilled water $+1.0 \%$ polyoxyethylene sorbitan monolaurate + $0.1 \%$ dodecylbenzene sulfonic acid and allowed to dry on a paper towel at room temperature. Control disks were only immersed in distilled water. The concentrations ranged from 0.10 to $20.00 \mathrm{mg} \mathrm{L}^{-1}$ (compounds $\mathbf{1 - 3 , 5}$ and 6), 1.00 to $70.00 \mathrm{mg} \mathrm{L}^{-1}$ (compounds $\mathbf{4 , 7 - 9}$ and 10) and 0.50 to $20.00 \mathrm{mg} \mathrm{L}^{-1}$ (azadirachtin). After drying, a treated disk and control disk were placed at a distance of $2.0 \mathrm{~cm}$ in each Petri dish. A larva was placed in the center of the Petri dish between the two leaf disks and was allowed to feed for $24 \mathrm{~h}$. Thirty repetitions were used for each treatment, with each repetition consisting of one Petri dish containing 
one larva. After $24 \mathrm{~h}$ of exposure, the larvae were removed, and the foliar areas of the leaves consumed in the control and treatment disks were evaluated. This evaluation was performed with the aid of the Licor-3100 leaf area meter, which presents high accuracy and repeatability with reading resolution ranging from 0.1 to $1 \mathrm{~mm}^{2}$. The feeding deterrence index (FDI) was calculated using the following formula: $\mathrm{FDI}=100[(\mathrm{C}-\mathrm{T}) /(\mathrm{C}+\mathrm{T})]$, in which $\mathrm{C}$ and $\mathrm{T}$ are the areas consumed on the control and treated disks, respectively. The results were compared with the positive control (azadirachtin).

\section{Statistical analysis}

To estimate the curve slopes of larvicidal, ovicidal and antifeedant assays, $\mathrm{LC}_{50}$ (lethal concentration) and $\mathrm{FDI}_{50}$ (feeding deterrence index) of each compound and positive control (azadirachtin and deltamethrin) were submitted to PROBIT analysis ${ }^{20}$ using SAS software version 9.0. ${ }^{21}$ The concentrations used were calculated based on the logarithmic series proposed by Robertson et al. ${ }^{16}$

\section{Results and Discussion}

Series of alkylations and acylations were performed to furnish the products shown in the Figure 1.

The alkylations of eugenol and thymol were performed in phase-transfer catalysis using $\mathrm{Bu}_{4} \mathrm{NHSO}_{4}$, polyethylene glycol. It was used either $\mathrm{K}_{2} \mathrm{CO}_{3}$, solid $\mathrm{KOH}$ or its solution in water. The reaction times strongly depended on the intensity of stirring. The compounds $\mathbf{1 - 5}$ and $\mathbf{8}$ were prepared in yield ranging from 31 to $87 \%$. The acylations were performed by simply mixing the substrates with the acyl halides in pyridine in the atmosphere of argon. The compounds 6, 7,9 and 10 were performed in yield ranging from 83 to $94 \%$. The derivatives were characterized by ${ }^{1} \mathrm{H}$ and ${ }^{13} \mathrm{C}$ NMR spectroscopy as well as high-resolution mass spectrometry (HRMS). In the ${ }^{1} \mathrm{H}$ NMR spectra, the hydrogen atoms of the methylene groups attached to carbonyl or oxygen were noticed as triplets within 2.59-2.71 and 3.99-4.09 ppm ranges, respectively. The carbon chemical shifts are compatible with the structures of the compounds. ${ }^{22-26}$ The spectroscopic data of derivatives are available in the Supplementary Information section.

The crystal structure determination of compound $\mathbf{5}$ had been performed at $173 \mathrm{~K}$ and revealed a complex chiral triclinic structure with $\mathrm{Z}=1$ and multiple disordered fragments (Figure 2).

The most relevant crystal data: formula: $\mathrm{C}_{28} \mathrm{H}_{38} \mathrm{O}_{4}$; $\mathrm{M}$ (molar mass $)=438.58$; triclinic; unit cell parameters: $\mathrm{a}=4.899(3), \mathrm{b}=10.286(5), \mathrm{c}=12.816(5) \AA, \alpha=97.792(19)^{\circ}$, $\beta=100.38(2)^{\circ}, \gamma=98.91(2)^{\circ}, V($ volume $)=618.7(5) \AA^{3}$, $\mathrm{T}($ temperature $)=173 \mathrm{~K}$; space group $=\mathrm{P} \overline{1}$ (No. 2$) ; \mathrm{Z}=1$; 87790 reflections measured; 5995 unique $\left(\mathrm{R}^{\text {int }}=0.038\right)$ used in all calculations. ${ }^{27-30} \mathrm{R}\left[F^{2}>2 \sigma\left(F^{2}\right)\right], \mathrm{wR}\left(F^{2}\right),=0.043$, 0.13 . In the crystal both crystallographically identical allyl groups are disordered with approximately 2:1 ratio of components. The details are shown in the Supplementary Information section.

Once prepared, the compounds were submitted to insecticidal assays to assess their larvicidal, ovicidal, and antifeedant effects.

Insecticidal activity and feeding deterrence

The median lethal concentrations $\left(\mathrm{LC}_{50}\right)$ (larvicidal and ovicidal) against Plutella xylostella estimated for the starting materials eugenol and thymol and their derivatives obtained through alkylation and acylation are displayed in Table 1.

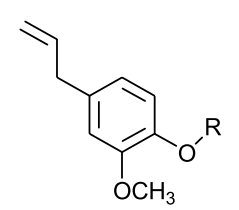

Eugenol $\mathrm{R}=\mathrm{H}$

1: $\mathrm{R}=\mathrm{C}_{4} \mathrm{H}_{9}$

2: $\mathrm{R}=\mathrm{C}_{10} \mathrm{H}_{21}$

3: $\mathrm{R}=\mathrm{C}_{16} \mathrm{H}_{33}$

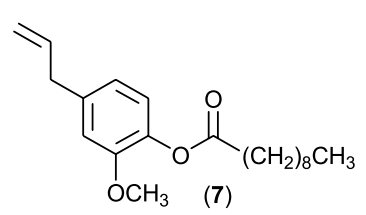

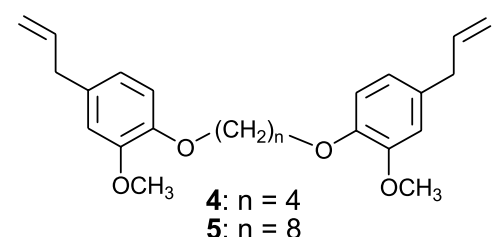

5: $n=8$<smiles>C=CCc1ccc(OC(C)=O)c(OC(C)=O)c1</smiles>

(6)<smiles>CC(=O)Oc1cc(C)ccc1C(C)C</smiles><smiles>CCCCCCCCCCCCCCCCCC(C)C</smiles>

(9)

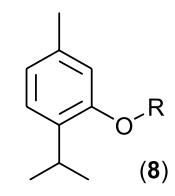

Thymol $\mathrm{R}=\mathrm{H}$

8: $\mathrm{R}=\mathrm{C}_{4} \mathrm{H}_{9}$

Figure 1. Chemical structures of eugenol, thymol and derivatives. 




Figure 2. Molecular structure of compound 5 with displacement ellipsoids.

Table 1. Larvicidal and ovicidal activity of compounds resulting from alkylation and acylation of eugenol and thymol and synthetic and plant-based insecticides (deltamethrin and azadirachtin)

\begin{tabular}{|c|c|c|c|c|c|c|}
\hline Compound & Bioassay & $\mathrm{N}$ & $\chi^{2}$ & D.F. & Slope \pm S.E. & $\mathrm{LC}_{50}(95 \%$ C.I. $) /\left(\mathrm{mg} \mathrm{L}^{-1}\right)$ \\
\hline \multirow{2}{*}{1} & larvicidal & 1080 & 1.93 & 7 & $1.46 \pm 0.07$ & $3.36(2.89-3.89)$ \\
\hline & ovicidal & 1620 & 2.60 & 7 & $1.50 \pm 0.06$ & $3.35(2.97-3.77)$ \\
\hline \multirow{2}{*}{2} & larvicidal & 1080 & 6.34 & 7 & $1.43 \pm 0.11$ & $4.31(3.79-4.91)$ \\
\hline & ovicidal & 807 & 12.04 & 7 & $1.41 \pm 0.10$ & $37.81(31.81-44.79)$ \\
\hline \multirow{2}{*}{3} & larvicidal & 1080 & 11.89 & 7 & $1.97 \pm 0.11$ & $6.03(5.41-6.72)$ \\
\hline & ovicidal & 1623 & 3.55 & 7 & $2.05 \pm 0.09$ & $63.71(58.45-69.41)$ \\
\hline \multirow{2}{*}{4} & larvicidal & 1080 & 10.93 & 7 & $2.39 \pm 0.15$ & $5.61(5.16-6.12)$ \\
\hline & ovicidal & 1622 & 11.86 & 7 & $2.51 \pm 0.12$ & $51.90(48.69-55.50)$ \\
\hline \multirow{2}{*}{5} & larvicidal & 824 & 3.23 & 5 & $1.04 \pm 0.07$ & $1.06(0.86-1.30)$ \\
\hline & ovicidal & 1583 & 10.34 & 7 & $1.25 \pm 0.05$ & $14.96(13.17-16.97)$ \\
\hline \multirow{2}{*}{6} & larvicidal & 1080 & 8.17 & 7 & $0.74 \pm 0.05$ & $7.07(5.31-9.16)$ \\
\hline & ovicidal & 1630 & 11.43 & 7 & $0.52 \pm 0.03$ & $3.30(2.50-4.38)$ \\
\hline \multirow{2}{*}{7} & larvicidal & 972 & 5.79 & 6 & $2.31 \pm 0.01$ & $2.58(2.20-3.06)$ \\
\hline & ovicidal & 1458 & 7.49 & 6 & $1.31 \pm 0.03$ & $5.18(4.54-5.93)$ \\
\hline \multirow{2}{*}{8} & larvicidal & 960 & 7.41 & 6 & $0.58 \pm 0.04$ & $5.24(3.65-7.33)$ \\
\hline & ovicidal & 1513 & 0.49 & 7 & $0.47 \pm 0.03$ & $2.44(1.78-3.38)$ \\
\hline \multirow{2}{*}{9} & larvicidal & 1200 & 8.31 & 8 & $0.45 \pm 0.03$ & $3.81(2.60-5.54)$ \\
\hline & ovicidal & 1404 & 0.81 & 7 & $0.32 \pm 0.03$ & $83.91(50.90-158.85)$ \\
\hline \multirow{2}{*}{10} & larvicidal & 1440 & 11.19 & 10 & $0.62 \pm 0.03$ & $2.70(2.08-3.54)$ \\
\hline & ovicidal & 2058 & 14.74 & 10 & $0.64 \pm 0.02$ & $2.75(2.22-3.42)$ \\
\hline \multirow{2}{*}{ Thymol } & larvicidal & 960 & 2.79 & 6 & $2.01 \pm 0.28$ & $27.94(23.62-32.74)$ \\
\hline & ovicidal & 1458 & 1.23 & 6 & $1.11 \pm 0.12$ & $46.66(32.51-61.88)$ \\
\hline \multirow{2}{*}{ Eugenol } & larvicidal & 840 & 4.89 & 5 & $2.00 \pm 0.11$ & $50.50(44.72-56.93)$ \\
\hline & ovicidal & 836 & 4.58 & 5 & $2.25 \pm 0.13$ & $96.02(83.98-110.80)$ \\
\hline \multirow{2}{*}{ Deltamethrin } & larvicidal & 836 & 4.66 & 5 & $1.52 \pm 0.09$ & $23.39(20.16-27.16)$ \\
\hline & ovicidal & 1498 & 7.36 & 8 & $1.03 \pm 0.04$ & $65.81(55.97-77.36)$ \\
\hline \multirow{2}{*}{ Azadirachtin } & larvicidal & 960 & 5.58 & 6 & $1.27 \pm 0.07$ & $11.26(9.46-13.42)$ \\
\hline & ovicidal & 1050 & 4.42 & 5 & $1.92 \pm 0.09$ & $30.78(27.52-34.43)$ \\
\hline
\end{tabular}

$\mathrm{N}$ : number of Plutella xylostella larvae or eggs; $\chi^{2}$ : chi-square; D.F.: degree of freedom; S.E.: standard error; LC: lethal concentration values; C.I.: confidence interval. 
The action of the compounds obtained through the derivatization of eugenol and thymol varied with the type of derivative and development stage of the pest. Third instar larvae were generally more susceptible to the eugenol and thymol derivatives than eggs. The only exception was acylated thymol derivative (10), which had the same level of toxicity independently of the development stage of the pest.

The eugenol derivatives exhibited significantly greater larvicidal and ovicidal toxicity compared to the starting material. Compound 5 was the most toxic to larvae, followed by compounds $\mathbf{1}$ and $\mathbf{2}$. On the other hand, in the ovicide tests, compound $\mathbf{1}$ was the most toxic, followed by compounds $\mathbf{2}$ and $\mathbf{5}$. Among the acylated derivatives, compound 7 was the most toxic to the larvae, followed by compound $\mathbf{6}$. The opposite result was found for these derivatives regarding ovicidal action.

The larvicidal and ovicidal properties of the derivatives of the monoterpene thymol were also enhanced by the chemical modifications. Compound $\mathbf{1 0}$ exhibited the greatest larvicidal action, followed by compounds $\mathbf{8}$ and 9, which had the same level of toxicity. Regarding ovicidal action, derivatives $\mathbf{8}$ and $\mathbf{1 0}$ were the most toxic and had the same level of toxicity. Comparing the results with those found for the starting material, derivatives $\mathbf{8 , 9}$ and 10 were more toxic to the larvae than thymol. Regarding ovicidal action, $\mathbf{8}$ and $\mathbf{1 0}$ were more potent than thymol, whereas derivative $\mathbf{9}$ had the same level of toxicity as the starting material.

In the comparison of the relative toxicity among all derivatives obtained in the present investigation, alkylated eugenol derivative 5 was the most toxic to the larvae, whereas alkylated eugenol derivative $\mathbf{1}$ and alkylated thymol derivative $\mathbf{8}$ were the most toxic to the eggs, followed by acylated eugenol derivative $\mathbf{6}$ and acylated thymol derivative 10, which had the same level of toxicity.

All alkylated and acylated derivatives of eugenol and thymol investigated herein had greater larvicidal toxicity than the synthetic insecticide deltamethrin $\left(\mathrm{LC}_{50}=23.39 \mathrm{mg} \mathrm{L}^{-1}\right)$ and the plant-based insecticide azadirachtin $\left(\mathrm{LC}_{50}=11.26 \mathrm{mg} \mathrm{L}{ }^{-1}\right)$. Regarding ovicidal action, compounds $\mathbf{8}$ and $\mathbf{1 0}$ derived from thymol exhibited greater toxicity than deltamethrin $\left(\mathrm{LC}_{50}=65.81 \mathrm{mg} \mathrm{L}^{-1}\right)$ and azadirachtin $\left(\mathrm{LC}_{50}=30.78 \mathrm{mg} \mathrm{L}^{-1}\right)$. However, compound 9 , obtained from the acylation of thymol, exhibited the same ovicidal activity as deltamethrin and less ovicidal activity compared to azadirachtin.

Eugenol and thymol show insecticidal activity as mentioned above, but there are no published data on their alkyl or acyl derivatives. Thus, it is of interest to investigate a series of alkylated and acylated derivatives of both to obtain potential lead compounds for further development. All synthesized products are nonpolar and more hydrophobic than the original eugenol and thymol, which presumably facilitates interactions with their targets. In addition, the absence of free $\mathrm{OH}$ group makes them less subject to oxidation.

The toxicity of these compounds is directly related to its form of penetration. In larvae, the toxic effect occurs through ingestion, penetration through the spiracles and contact with the integument. ${ }^{31}$ Penetration in eggs only occurs through spaces in the exochorion of the integumentary layer. ${ }^{32}$ Therefore, the greater susceptibility of the $P$. xylostella larvae to the eugenol and thymol derivatives investigated herein compared to the eggs may be explained by the different forms of penetration of these compounds in the larval stage.

The results of the analysis of the eugenol derivatives suggest a greater toxic effect on larvae and eggs for the dimer ether (compound 5) compared to the homolog derivate (compound 4), which may be associated with the greater quantity of carbon among the units of eugenol. These results also show that derivatives with more than one unit of eugenol were more efficient, reaching 47.6fold greater toxicity to the larvae compared to the starting material.

The greater ovicidal activity found for the eugenol derivate obtained due to the protection of the phenolic hydroxyl group by a butyl group (compound 1) shows that activity depends on the size of the allopathic chain, as compound $\mathbf{1}$ with the butyl group had the greatest ovicidal activity, followed by compound $\mathbf{2}$ with the decyloxy group and compound $\mathbf{3}$ with the hexadecyloxy group. Another point to consider regarding the ovicidal activity of these derivatives that proved to be inverse to the aliphatic chain used in the protection of the phenolic hydroxyl group of eugenol is the relation between compound $\mathbf{1}$, with a smaller aliphatic chain, and the spaces in the hydrophobic crystalline network of the integumentary layer of the egg.

The better results regarding larvicidal and ovicidal action for compounds $\mathbf{1}$ and $\mathbf{5}$ suggest that the protection of the phenolic hydroxyl group of eugenol in the formation of ether derivatives enhances the insecticidal property of eugenol. These results are in agreement with eugenol derivatives obtained by Barbosa et al., ${ }^{33}$ who evaluated the insecticidal activity against larvae of the dengue fever vector (Aedes aegypti) and found that the ether derivate (1-ethoxy-2-methoxy-4-(2-propen-1-yl)-benzene) exhibited the greatest activity and was even more toxic than eugenol. Likewise, Vargas-Méndez et al. ${ }^{34}$ obtained eugenol derivatives through the protection of phenolic hydroxyl and found greater insecticidal activity against larvae of Spodoptera frugiperda compared to the starting material. 
A similar explanation is given for the ovicidal and larvicidal activity of the alkylated and acylated derivatives of thymol. The greater ovicidal activity of compound $\mathbf{8}$ was due to the addition of a lipophilic butyl group, whereas the greater larvicidal activity of the ester derivate compound $\mathbf{1 0}$ may be explained by the presence of two thymol units, as the activity of this compound was 1.41 -fold greater than that found for compound $\mathbf{9}$, which had one thymol unit.

There are no reports in the literature on synthetic derivatives of thymol with action against arthropods. However, Kumbhar and Dewang ${ }^{35}$ and Kaur et al. ${ }^{36}$ report the enhancement of thymol derivatives achieved through alkylation and acylation against fungi and bacteria.

\section{Feeding deterrence}

The median antifeedant concentrations $\left(\mathrm{AC}_{50}\right)$ against Plutella xylostella estimated for the starting materials eugenol and thymol and their derivatives obtained through alkylation and acylation are displayed in Table 2 .

The antifeedant action of the compounds obtained through the derivatization of eugenol and thymol varied with the derivative. Derivatives 1, 2, 3, 4 and 6 exhibited better antifeedant action than the starting material (eugenol). The following is the decreasing order of antifeedant action found for the alkylated and acylated eugenol derivatives: $\mathbf{6}>\mathbf{1}=\mathbf{3}>\mathbf{2}=\mathbf{4}>\mathbf{5}=\mathbf{7}$. Regarding the thymol derivatives, only compound $\mathbf{8}$ had better antifeedant activity than the starting material. Moreover, the antifeedant activity of compound $\mathbf{1 0}$ did not differ significantly from thymol.
The following is the decreasing order of antifeedant action found for the thymol derivatives: $\mathbf{8}>\mathbf{1 0}>\mathbf{9}$.

In the comparison of these results to the positive controls, the derivatives were more efficient than the synthetic insecticide deltamethrin, which had no antifeedant activity. However, most eugenol derivatives exhibited less antifeedant action compared to the plant-based insecticide azadirachtin. The only exception was acylated eugenol derivative $\mathbf{6}$, which exhibited the same antifeedant action as azadirachtin. Among the thymol derivatives, acylated compound 10 exhibited the same antifeedant action as the plant-based insecticide, whereas compound 8 was 1.5-fold more potent than azadirachtin.

The antifeedant effect is an important property for use in integrated pest management. This property affects the behavior of the insect, keeping it away from plants and minimizing damage. ${ }^{37}$ Among the eugenol and thymol derivatives, the better antifeedant action found for the alkylated thymol derivate compound $\mathbf{8}$ compared to its analog, eugenol derivate compound $\mathbf{1}$, may be attributed to the starting material. In this investigation, thymol exhibited 3.74-fold greater antifeedant activity compared to eugenol. Kanda et al. ${ }^{38}$ also found this greater antifeedant property of thymol compared to eugenol analyzing three storage grain pests (Sitophilus oryzae, Tribolium castaneum and Rhyzopertha dominica).

Despite the significant number of investigations addressing the effects of essential oils rich in eugenol on the behavior of $P$. xylostella, ${ }^{39,40}$ we found no previous studies on the antifeedant action of synthetic ether and

Table 2. Antifeedant activity of compounds resulting from alkylation and acylation of eugenol and thymol and synthetic and plant-based insecticides (deltamethrin and azadirachtin)

\begin{tabular}{|c|c|c|c|c|c|}
\hline Compound & $\mathrm{N}$ & $\chi^{2}$ & D.F. & Slope \pm S.E. & $\mathrm{AC}_{50}(95 \%$ C.I. $) /\left(\mathrm{mg} \mathrm{L}^{-1}\right)$ \\
\hline 1 & 30 & 8.92 & 7 & $2.92 \pm 0.19$ & $12.38(11.52-13.31)$ \\
\hline 2 & 30 & 4.16 & 7 & $2.93 \pm 0.22$ & $15.17(14.15-16.27)$ \\
\hline 3 & 30 & 6.81 & 7 & $4.21 \pm 0.24$ & $11.71(11.08-12.40)$ \\
\hline 4 & 30 & 0.85 & 7 & $4.58 \pm 0.28$ & $17.20(16.40-18.08)$ \\
\hline 5 & 30 & 3.01 & 7 & $1.74 \pm 0.10$ & $40.66(35.87-46.01)$ \\
\hline 6 & 30 & 3.12 & 7 & $1.70 \pm 0.16$ & $4.29(3.83-4.84)$ \\
\hline 7 & 30 & 5.31 & 7 & $3.83 \pm 0.22$ & $41.51(39.13-44.06)$ \\
\hline 8 & 30 & 1.06 & 7 & $2.81 \pm 0.18$ & $3.30(3.04-3.55)$ \\
\hline 9 & 30 & 6.43 & 7 & $0.61 \pm 0.08$ & $21.46(13.87-42.27)$ \\
\hline 10 & 30 & 4.77 & 7 & $2.15 \pm 0.18$ & $6.52(5.86-7.41)$ \\
\hline Thymol & 30 & 7.91 & 6 & $1.55 \pm 0.14$ & $6.38(4.32-8.36)$ \\
\hline Eugenol & 30 & 0.29 & 5 & $1.21 \pm 0.11$ & $23.87(18.69-29.41)$ \\
\hline Deltamethrin $^{\mathrm{a}}$ & - & - & - & - & - \\
\hline Azadirachtin & 30 & 2.47 & 5 & $1.58 \pm 0.10$ & $5.14(4.39-6.05)$ \\
\hline
\end{tabular}

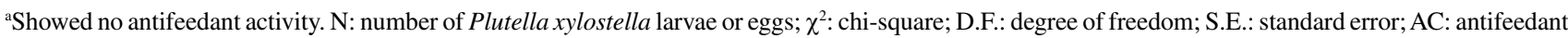
concentration values; C.I: confidence interval. 
ester derivatives of eugenol through the protection of the hydroxyl group of phenol. However, the results of the present study for these derivatives suggest that the obtainment of a dimer ester of eugenol enhances its antifeedant action.

\section{Conclusions}

As a conclusion, two lead compounds for further development were identified. The most promising in larvicidal test is eugenol derivative 5, 1,1'-[1,8-octanediylbis(oxy)]bis(4-allyl-2-methoxy-benzene), which was 22-fold more and 10 -fold more potent than deltamethrin and azadirachtin, respectively. In the ovicidal test, the most promising is thymol derivative 8, 1-butoxy-2-isopropyl-5-methylbenzene, which is 27 -fold more and 12 -fold more potent than deltamethrin and azadirachtin, respectively. The compounds obtained are weakly antifeedant. Only $\mathbf{8}$ is 1.5-fold more active than azadirachtin. These results direct attention to both lead compounds for further development in terms of variation of the number of the $-\left(\mathrm{CH}_{2}\right)$ - groups in the bis-alkylated compounds similar to $\mathbf{5}$, and variation of the length of the alkyl moiety in the ether $\mathbf{8}$ hoping to further improve the activity profile of the final compounds against the $P$. xylostella. This work is in progress.

Through the different approaches used in the obtainment of alkylated and acylated derivatives of thymol and eugenol, it was possible to enhance the antifeedant action of these essential oil constituents against larvae as well as the insecticidal activity against different development stages of P. xylostella. The present insecticidal evaluation of derivatives of eugenol and thymol could be useful for future investigations in the search for compounds with biological properties against this important pest of brassicas.

\section{Supplementary Information}

Crystallographic data (excluding structure factors) for the structures in this work were deposited in the Cambridge Crystallographic Data Centre as supplementary publication number CCDC 2006471. Copies of the data can be obtained, free of charge, via https://www.ccdc.cam. ac.uk/structures/.

Supplementary information is available free of charge at http://jbcs.sbq.org.br as a PDF file.

\section{Acknowledgments}

This work was supported by Conselho Nacional de Desenvolvimento Científico e Tecnológico (CNPq, PQ-2 - 302735/2019-4), Coordenação de Aperfeiçoamento de Pessoal de Nível Superior (CAPES, 88887.368587/201900) and Fundação de Amparo à Ciência e Tecnologia do Estado de Pernambuco (FACEPE, BCT-0253-1.06/19; APQ-08601.06/16; APQ-0398-1.06/19).

\section{Author Contributions}

Claudio A. G. Camara, João P. R. Melo and Bogdan Doboszewski conceived and designed the experiment; Bogdan Doboszewski and Alexander Y. Nazarenko performed the synthesis; João P. R. Melo and Rodrigo B. Santos performed the insecticidal study; Claudio A. G. Camara, João P. R. Melo, Marcilio M. Moraes, Alexander Y. Nazarenko and Bogdan Doboszewski analyzed the data; Claudio A. G. Camara, João P. R. Melo and Bogdan Doboszewski participated in writing-original draft preparation; Claudio A. G. Camara, Marcilio M. Moraes and Bogdan Doboszewski participated in writing-review and editing.

\section{References}

1. Reddy, G. V.; Integrated Management of Insect Pests on Canola and Other Brassica Oilseed Crops; CABI: Oxfordshire, 2017.

2. Holtz, A. M.; Rondelli, V. M.; Celestino, F. N.; Bestete, L. R.; de Carvalho, J. R.; Pragas das Brássicas, $1^{\text {st }}$ ed.; Instituto Federal de Ensino, Ciência e Tecnologia do Espírito Santo: Colatina, Espírito Santo, Brazil, 2015.

3. Neto, J. E. L.; Amaral, M. H.; Siqueira, H. A.; Barros, R.; Silva, P. A.; Phytoparasitica 2016, 44, 631.

4. Cavalcanti, S. C. H.; Niculau, E. D. S.; Blank, A. F.; Câmara, C. A. G.; Araújo, I. N.; Alves, P. B.; Bioresour. Technol. 2010, $101,829$.

5. Eftekhari, M.; Ardekani, M. R. S.; Amin, M.; Attar, F.; Akbarzadeh, T.; Safavi, M.; Khanavi, M.; Iran. J. Pharm. Res. 2019, 18, 412.

6. Pavela, R.; Bartolucci, F.; Desneux, N.; Lavoir, A. V.; Canale, A.: Maggi, F.; Benelli, G.; Ind. Crops Prod. 2019, 138, 111460.

7. Kaur, K.; Kaushal, S.; J. Pharmacogn. Phytochem. 2019, 8, 398.

8. Scalvenzi, L.; Radice, M.; Toma, L.; Severini, F.; Boccolini, D.; Bella, A.; Guerrini, A.; Tacchini, M.; Sacchetti, G.; Chiurato, M.; Romi, R.; Di Luca, M.; Parasite 2019, 26, 23.

9. Yotavong, P.; Boonsoong, B.; Pluempanupat, W.; Koul, O.; Bullangpoti, V.; Int. J. Pest. Manage. 2015, 61, 171.

10. Somjit, C.; Kumrungsee, N.; Pluempanupat, W.; Bullanpotil, V.; Commun. Agric. Appl. Biol. Sci. 2015, 80, 187.

11. Badgujar, R. H.; Mendki, P. S.; Kotkar, H. M.; Biopestic. Int. 2017, 13, 113.

12. Dey, D.; Gupta, M. K.; Innovative Farming 2016, 1, 21.

13. Lobo, A. P.; da Camara, C. A. G.; de Melo, J. P. R.; de Moraes, M. M.; J. Plant. Dis. Protect. 2019, 126, 79. 
14. Silva, C. B. D.; Moraes, M. M. D.; da Camara, C. A. G.; Ribeiro, N. D. C.; de Melo, J. P.; de Lima, V. L.; Navarro, D. M.; Quim. Nova 2019, 42, 313.

15. Pandiyan, G. N.; Mathew, N.; Munusamy, S.; Ecotoxicol. Environ. Saf. 2019, 174, 549.

16. Robertson, J. L.; Jones, M. M.; Olguin, E.; Alberts, B.; Bioassays with Arthropods, $3^{\text {rd }}$ ed.; CRC Press: Boca Raton, USA, 2017.

17. Bandeira, G. N.; da Camara, C.A. G.; de Moraes, M. M.; Barros, R.; Muhammad, S.; Akhtar, Y.; J. King Saud Univ., Sci. 2013, 25,83 .

18. Zago, H. B.; Barros, R.; Torres, J. B.; Pratissoli, D.; Neotrop. Entomol. 2010, 39, 241.

19. Akhtar, Y.; Pages, E.; Stevens, A.; Bradbury, R. O. D.; da Camara, C. A. G.; Isman, M. B.; Physiol. Entomol. 2012, 37, 81.

20. Finney, D. J.; Probit Analysis, $3^{\text {rd }}$ ed.; University Press: Cambridge, 1971.

21. SAS Software, version 9.0; SAS Institute Inc., Cary, USA, 2002.

22. Raja, M. R. C.; Velappan, A. B.; Chellappan, D.; Debnath, J.; Mahapatra, S. K.; Eur. J. Med. Chem. 2017, 139, 503.

23. Liu, T.; Hao, C.; Wang, L.; Li, Y.; Liu, W.; Xin, J.; Zhang, J.; Macromolecules 2017, 50, 8588.

24. Varma, I. K.; Gupta, S. P.; Varma, D. S.; Angew. Makromol. Chem. 1991, 184, 7.

25. More, D. H.; Pawar, N. S.; Dewang, P. M.; Patil, S. L; Mahulikar, P. P.; Russ. J. Gen. Chem. 2004, 74, 217.

26. Kumbhar, P. P.; Kapadi, U. R.; Hundiwale, D. G.; Attare, S. B.; Dewang, P. M.; Pawar, N. S.; Org. Prep. Proced. Int. 2000, 32, 600 .
27. Dolomanov, O. V.; Bourhis, L. J.; Gildea, R. J.; Howard, J. A. K.; Puschmann, H.; J. Appl. Crystallogr. 2009, 42, 339.

28. Krause, L.; Herbst-Irmer, R.; Sheldrick, G. M.; Stalke, D. J.; J. Appl. Crystallogr. 2015, 48, 3.

29. Sheldrick, G. M.; Acta Crystallogr., Sect. C 2015, C71, 3.

30. Sheldrick, G. M.; Acta Crystallogr., Sect. A 2015, A71, 3.

31. Yu, J. S.; The Toxicology and Biochemistry of Insecticides, $2^{\text {nd }}$ ed.; CRC Press: Boca Raton, USA, 2014.

32. Nation, J. L.; Insect Physiology and Biochemistry, $3^{\text {rd }}$ ed.; CRC Press: New York, USA, 2015.

33. Barbosa, J. D.; Silva, V. B.; Alves, P. B.; Gumina, G.; Santos, R. L.; Sousa, D. P.; Cavalcanti, S. C.; Pest Manage. Sci. 2012, $68,1478$.

34. Vargas-Méndez, L. Y.; Sanabria-Flórez, P. L.; Saavedra-Reyes, L. M.; Merchan-Arenas, D. R.; Kouznetsov, V. V.; Saudi J. Biol. Sci. 2019, 26, 1613.

35. Kumbhar, P. P.; Dewang, P. M.; J. Sci. Ind. Res. 2001, 60, 645.

36. Kaur, R.; Darokar, M. P.; Chattopadhyay, S. K.; Krishna, V.; Ahmad, A.; Med. Chem. Res. 2014, 23, 2212.

37. Koul, O. In Ecofriendly Pest Management for Food Security; Omkar, ed.; Academic Press: London, 2016, p. 525.

38. Kanda, D.; Kaur, S.; Koul, O.; J. Pest Sci. 2017, 90, 531.

39. Walia, S.; Saha, S.; Tripathi, V.; Sharma, K. K.; Phytochem. Rev. 2017, 16, 989.

40. Sangha, J. S.; Astatkie, T.; Cutler, G. C.; Can. Entomol. 2017, 149,639

Submitted: July 20, 2021

Published online: October 4, 2021 